\title{
基于土壤墒情抗差的降雨径流预报模型——设计与实验流域应用”
}

\author{
沈丹丹 ${ }^{1}$, 包为民 ${ }^{1}$, 江 鹏 $^{3}$, 张 阳 $^{2}$, 费如君 ${ }^{2}$ \\ (1: 河海大学水文水资源学院, 南京 210098) \\ (2: 中国电建集团中南勘测设计研究院有限公司, 长沙 410014) \\ (3:Desert Research Institute, Las Vegas Nevada USA, 89119)
}

\begin{abstract}
摘 要: 本文旨在将实时监测得到的土壤墒情转化为流域水文模型可以直接使用的土壤含水量,论证将实时土壤墒情资 料用于实时预报的可行性; 利用实时监测土壤墑情, 改进传统的模型结构, 设计基于实测土壤墑情的降雨径流水文预报 模型. 采用土壤含水量误差抗差估计技术以抵御观测资料粗差的影响, 提高系统的稳定性; 并在此基础上提出了土壤含 水量系统响应修正方法, 以提高模型计算精度. 将该模型应用于实验流域一一宝盖洞流域进行应用检验, 洪水模拟合格 率达到 $92.3 \%$, 整体模拟精度达到甲级.
\end{abstract}

关键词: 土壤墑情; 土壤墒情抗差; 土壤含水量修正; 系统响应曲线; 降雨径流预报模型; 洪水预报

\section{Rainfall-runoff forecast model based on robust correction of soil moisture:Design and ap- plication in an experimental basin}

\author{
SHEN Dandan ${ }^{1}$, BAO Weimin ${ }^{1}$, JIANG Peng ${ }^{3}$, ZHANG Yang ${ }^{2} \&$ FEI Rujun ${ }^{2}$ \\ (1: College of Water Resources and Hydrology, Hohai University, Nanjing 210098, P.R.China) \\ (2: Power China Zhongnan Engineering Corporation Limited, Changsha 410014, P.R.China) \\ (3: Desert Research Institute, Las Vegas Nevada USA, 89119)
}

\begin{abstract}
This study is aimed to convert the real-time measured soil moisture into the soil water content which can be used directly in the watershed hydrological model, and demonstrate the feasibility of using the real-time measured soil moisture for real-time forecasting. In this paper, a rainfall-runoff hydrological forecasting model based on the measured soil moisture is proposed to improve the structure of the traditional model. The soil moisture robust estimation technique is used to resist the influence of gross error, and improve the stability of the system. On that basis, a soil water content error correction method based on a system response curve is introduced into the model to improve the accuracy of the model. The model is applied in an experimental basin named Baogaidong Basin. The result indicates that the qualification rate of basin flood simulation reaches $92.3 \%$, and the overall simulation accuracy reaches Class A.
\end{abstract}

Keywords: Measured soil moisture; robust correction of soil moisture; soil water content error correction; system response curve; rainfall-runoff forecast model; flood forecasting

在水文模拟和水文预报中, 土壤含水量作为洪水预报模型的一个状态量, 对预报结果有着不可忽视的 影响, 尤其是流域内前期土湿对洪水预报精度有很大的影响 ${ }^{[1]}$. 现有水文预报模型系统大多是基于气象资 料经模型计算得出土壤含水量情况, 缺乏土壤含水量模拟检验, 更缺乏对基于土壤墑情实时监测的水文预 报模型应用研究. 然而经模型计算得到的土壤含水量毕竟与实际土壤含水量存在偏差, 而且可能会出现随 着时间的推移误差不断积累的现象, 直接影响净雨计算的准确性, 给水文预报结果带来误差, 从而影响洪水 预报的整体预报精度 ${ }^{[2]}$. 因此, 利用实时监测的土壤墑情资料, 改进传统的模型结构, 减少土壤含水量的模 拟误差对洪水预报结果产生的不良影响成为洪水预报重要的研究课题.

* 国家重点研发计划专项 (2016YFC0402703) 和国家自然科学基金项目 (41371048,51479062) 联合资助. 2016 - 1209 收稿;2017-02-19 收修改稿. 沈丹丹(1992 ), 女,博士研究生; E-mail:ddshen92@ 163.com. 
Jackson 等 $^{[3]}$ 在改进水文模拟时最早采用同化土壤含水量的方法,他采用直接插人的同化方法, 将实际 观测的土壤含水量代替由水文模型模拟出的土壤含水量, 以此提高模型计算精度. Pauwels 等 ${ }^{[4]}$ 利用统计校 正法与牛顿松他法两种同化方法将 ERS 卫星微波遥感所获得的土壤含水量与基于 TOPMODEL 的 TOPLATS 模型的数据进行同化, 通过比较发现集总式与分布式两个版本的 TOPMODEL 模型在同化了遥感反演的土 壤含水量数据之后, 均可以提高水文预报的精度. Parajka 等 ${ }^{[5]}$ 通过对奥地利 320 个流域进行径流试验研究, 表明卫星微波遥感 $25 \mathrm{~km}$ 分辨率土壤含水量数据对流域水文预报有一定的作用. 数据同化的主要工作是把 各种来源不同、误差时间信息不同或者空间分辨率不同的观测资料融人一个数值动力模型中利用数学方法 进行计算, 从而在实际观测值与模型解之间找到一个最优解. 但数据同化技术对土壤含水量的修正并不能 直接用于水文模型, 因为遥感技术观测的土壤含水量数据与水文模型中的土壤含水量并不是同一个概念, 例如, 新安江模型中土壤含水量是指蓄水深度 $(\mathrm{mm})$, 且目前还没有能够将遥感观测的土壤水数据转换成洪 水预报模型中的值的有效手段 ${ }^{[2]}$.

此外, 由于现有观测技术尚不成熟、观测设备不够先进, 导致实测土壤墑情数据存在较大的粗差, 若不 经过抗差处理,无法用于水文模型计算. 本文采用抗差技术对观测资料进行处理,利用抗差技术所具有的误 差抗御性, 减少观测粗差对预报系统的影响, 并采用系统响应反演修正方法修正初始土壤含水量, 以提高模 型的预报精度.

\section{1 方法介绍}

\section{1 土壤墑情资料抗差技术}

抗差模型的建立主要涉及土壤含水率的分布关系, 本研究中抗差模型结构采用多元回归模型:

$$
\theta C_{i, t}=\alpha_{1} \cdot \theta_{1, t}+\alpha_{2} \cdot \theta_{2, t}+\cdots+\alpha_{i-1} \cdot \theta_{i-1, t}+\alpha_{i+1} \cdot \theta_{i+1, t}+\cdots+\alpha_{m} \cdot \theta_{m, t}
$$

式中, $\theta C_{i, t}$ 为待估计的土壤含水率, $i$ 为估计变量序号, $\theta_{k, t}(k=1 、 2 、 \cdots, i-1 、 i+1, \cdots, m)$ 为观测的土壤含水 率, $\alpha_{k}(k=1 、 2 、 \cdots 、 i-1 、 i+1 、 \cdots, m)$ 为待估计的常系数, $m$ 为回归变量个数.

考虑到流域内土壤含水率所有测站、垂线上所有测点之间都存在相关性, 所以变量个数 $m$ 最大值是所 有测站垂线测点的总和. 但由于测站垂线测点的相关性存在差异, 贡献度也不同, 所以回归建模采用逐步回 归方法建模, 使得所选择的每个变量都是具有重要贡献度, 贡献度小的变量被剔除. 这样, 对序号为 $i$ 的估计 变量 $\theta C_{i, t}$, 通过逐步回归建模, 其变量的个数也是随 $i$ 变化的 $m(i)$. 逐步回归建模, 就可获得一系列变量个 数不同的回归模型 ${ }^{[-8]}$.

本研究采用 Hampel 估计, 其抗差权函数 ${ }^{[9]}$ 为:

$$
\omega(u)=\left\{\begin{array}{cc}
1, & |u| \leqslant a \\
a /|u|, & a<|u| \leqslant b \\
\frac{a(c-|u|)}{(c-b)|u|}, & b<|u| \leqslant c \\
0, & |u|>c
\end{array}\right.
$$

式中, $u$ 为观测值残差, $a 、 b$ 和 $c$ 为 3 个参数, 即: 当观测值残差绝对值 $|u|$ 不大于 $a$ 时, 等价权取原观测权; $|u|$ 在 $a$ 与 $b$ 之间时, 采用绝对和极小法 (也是稳健估计) ; $|u|$ 在 $b$ 与 $c$ 之间时, 等价权随着残差的增大而减小, 从而限制这部分观测值对 参数的影响; $|u|$ 大于 $c$ 时, 观测值不予采用 ${ }^{[10]}$. 这些常参数要预 先通过实际资料进行分析确定, 而且在选取时要考虑抗差性和风 险的平衡,对于不同的观测变量 $\theta C_{i, t}$, 其相应的误差分布不同,参 数值也随之变化. 所以, 严格意义上说, 这是 3 个变参数.

\section{2 土壤含水量系统响应反演方法}

如图 1 所示, 将新安江模型作为一个系统, 通过给初始土壤含 水量 $W_{0}$ 一个单位的变化量, 使得模型的产流系列 $R$ 发生变化, 进 一步使得计算的流量系列 $Q_{\mathrm{c}}$ 在原始计算结果上产生的变化就称

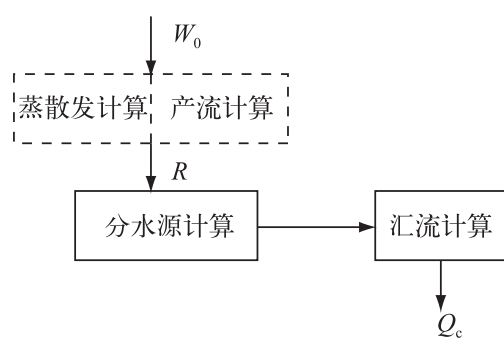

图 1 系统示意图

Fig.1 Schematic diagram of the system 
为系统响应, 而变化后的流量系列与原始计算流量系列之差则称为初始土壤含水量的系统响应曲线 ${ }^{[2]}$.

在模型的输人变量和状态变量中只考虑土壤含水量对预报的影响,将上述系统归纳如下:

$$
Q(t)=Q(W, \lambda, t)
$$

式中, $Q$ 为流域出口断面流量, $W$ 为土壤含水量, $\lambda$ 为模型参数, $t$ 为时间.

由于新安江模型考虑了降雨和下垫面分布不均的特性, 将计算流域划分为多个单元流域, 对应于每个 单元有其相应的初始土壤含水量,因此,对各单元的初始土壤含水量进行分单元修正.

对式(3) 进行微分处理,如下:

$$
\mathrm{d} Q(W, \lambda, t)=\left.\frac{\mathrm{d} Q}{d W}\right|_{W=W_{0}} \mathrm{~d} W
$$

将样本长度为 $L$ 的 $Q(t)=\left[Q_{1}, Q_{2}, \cdots, Q_{L}\right]^{T}, W=\left[W_{1}, W_{2}, \cdots, W_{m}\right]^{T}$ 及 $W_{0}=\left[W_{1,0}, W_{2,0}, \cdots, W_{m, 0}\right]^{T}$ 的分 量计算代人式(4)中,可得:

$$
\left\{\begin{array}{c}
Q(W, \lambda, 1)=Q\left(W_{0}, \lambda, 1\right)+\left.\frac{\partial Q(W, \lambda, 1)}{\partial W_{1}}\right|_{W=W_{0}} \Delta W_{1}+\left.\frac{\partial Q(W, \lambda, 1)}{\partial W_{2}}\right|_{W=W_{0}} \Delta W_{2}+\cdots+ \\
\left.\frac{\partial Q(W, \lambda, 1)}{\partial W_{m}}\right|_{W=W_{0}} \Delta W_{m}+e_{1} \\
Q(W, \lambda, 2)=Q\left(W_{0}, \lambda, 2\right)+\left.\frac{\partial Q(W, \lambda, 2)}{\partial W_{1}}\right|_{W=W_{0}} \Delta W_{1}+\left.\frac{\partial Q(W, \lambda, 2)}{\partial W_{2}}\right|_{W=W_{0}} \Delta W_{2}+\cdots+ \\
\left.\frac{\partial Q(W, \lambda, 2)}{\partial W_{m}}\right|_{W=W_{0}} \Delta W_{m}+e_{2} \\
Q(W, \lambda, L)=Q\left(W_{0}, \lambda, L\right)+\left.\frac{\partial Q(W, \lambda, L)}{\partial W_{1}}\right|_{W=W_{0}} \Delta W_{1}+\left.\frac{\partial Q(W, \lambda, L)}{\partial W_{2}}\right|_{W=W_{0}} \Delta W_{2}+\cdots+ \\
\left.\frac{\partial Q(W, \lambda, L)}{\partial W_{m}}\right|_{W=W_{0}} \Delta W_{m}+e_{L}
\end{array}\right.
$$

式(5) 可写成如下矩阵形式:

$$
Q(W, \lambda, t)=Q\left(W_{0}, \lambda, t\right)+U \cdot \Delta W+E
$$

式中, $Q(W, \lambda, t)$ 表示实测出口断面流量过程, 简写为 $Q_{0} ; Q\left(W_{0}, \lambda, t\right)$ 表示模型计算流量过程, 即 $Q_{\mathrm{c}}$; 系统响 应矩阵 $U=\left[\begin{array}{cccc}\frac{\partial Q(W, \lambda, 1)}{\partial W_{1}} & \frac{\partial Q(W, \lambda, 1)}{\partial W_{2}} & \cdots & \frac{\partial Q(W, \lambda, 1)}{\partial W_{m}} \\ \frac{\partial Q(W, \lambda, 2)}{\partial W_{1}} & \frac{\partial Q(W, \lambda, 2)}{\partial W_{2}} & \cdots & \frac{\partial Q(W, \lambda, 2)}{\partial W_{m}} \\ \vdots & \vdots & \cdots & \vdots \\ \frac{\partial Q(W, \lambda, L)}{\partial W_{1}} & \frac{\partial Q(W, \lambda, L)}{\partial W_{2}} & \cdots & \frac{\partial Q(W, \lambda, L)}{\partial W_{m}}\end{array}\right]$, 初始土壤含水量变化量 $\Delta W=\left[\Delta W_{1}, \Delta W_{2}\right.$, $\left.\cdots, \Delta W_{m}\right]^{T} ; E=\left[e_{1}, e_{2}, \cdots, e_{L}\right]^{T}$ 为随机误差项.

$U$ 矩阵中的每一项可以通过差分近似微分求解:

$$
\left.\frac{\partial Q(W, \lambda, t)}{\partial W_{i}}\right|_{W=W_{0}}=\frac{Q\left(\left(W_{1,0}, \cdots, W_{i, 0}+\Delta W_{i}, \cdots, W_{m, 0}\right), \lambda, t\right)-Q\left(\left(W_{1,0}, \cdots, W_{i, 0}, \cdots, W_{m, 0}\right), \lambda, t\right)}{\Delta W_{i}}
$$

式中, $t=1,2, \cdots, L$ 为时间尺度; $i=1,2, \cdots, m$ 为空间尺度.

$U$ 矩阵的具体计算过程为: 在保持其他单元值不变的情况下分别给每个单元的初始土壤含水量增加一 个单位量, 用改变后的初始值作为新安江模型的输人进行计算, 模拟得到的新流量系列与原始模型计算流 量系列的差值为该单元初始土壤含水量的系统响应曲线, 作为系统响应矩阵 $U$ 中对应于该单元初始土壤含 水量的一列参与计算 ${ }^{[11-15]}$.

初始土壤含水量的修正量 $\Delta W$ 可根据最小二乘估计求得： 


$$
\Delta W=\left(U^{T} U\right)^{-1} U^{T}\left(Q(W, \lambda, t)-Q\left(W_{0}, \lambda, t\right)\right)
$$

由此可得修正后的初始土壤含水量 $\left(W_{0}^{\prime}\right)$ 为:

$$
W_{0}^{\prime}=W_{0}+\Delta W
$$

则修正流量系列 $\left(Q_{c}^{\prime}\right)$ 为:

$$
Q_{\mathrm{c}}^{\prime}=Q\left(W_{0}^{\prime}, \lambda, t\right)
$$

\section{2 基于土壤含水量的降雨径流预报模型建立}

本研究以典型的概念性水文模型—三水源新安江模型为基础, 设计基于土壤含水量的降雨径流预报 模型. 三水源新安江模型蒸散发计算采用三层蒸发模型; 产流计算采用蓄满产流模型; 径流划分采用自由水 蓄水库结构将总径流划分为地表径流、壤中流和地下径流 3 种; 流域汇流采用线性水库; 河道汇流采用马斯 京根分段连续演算法 ${ }^{[16]}$. 具体的建模步骤如下:

1)采用观测的同步土壤墑情、雨量、径流资料分析径流、降雨与实测土壤墑情的关系. 由于实测土壤墑 情资料存在较大的观测误差, 采用抗差分析方法, 对观测误差进行抗差估计, 以减小观测误差对土壤含水量 估计的影响.

2) 采用流域实测土壤墑情及雨洪资料进行模型分析计算, 确定模型参数 ${ }^{[17-20]}$. 根据建立的模型计算出 每场洪水的逐小时土壤含水量.

3) 建立抗差后的实测土壤含水率 $\theta$ 与模型计算土壤含水量 $W$ 之间的函数关系; 并根据该函数关系, 用 实测土壤含水率推算模型土壤含水量,作为新安江模型的输人进行洪水模拟.

4) 采用土壤含水量系统响应反演修正方法, 改进洪水初始时刻的土壤含水量, 以提高预报模型的模拟 精度.

\section{3 模型应用与检验}

\section{1 实验流域概况}

本文实验流域为宝盖洞流域, 位于汶阳市古港镇宝盖洞村, 为洞庭湖水系湘江支流汶阳河一级支流宝 盖河的宝盖水文站以上流域,水文站以上河长约 $6.8 \mathrm{~km}$, 流域控制集水面积 $22.1 \mathrm{~km}^{2}$, 流域高程在 200 1200 $\mathrm{m}$. 流域内基本属自然生态, 典型山地, 植被茂密, 坡陡沟深, 河流短促, 有 2 级小拦河坝及微小型引水式水力 发电站,无水库. 宝盖河流域地处亚热带季风气候 区,具有湿热多雨、夏热冬寒的特点,暴雨频繁,洪 水由暴雨产生,具有陡涨陡落的特点. 宝盖洞水文 站测验河流属山溪性小河, 水位随洪水暴涨暴落. 1954 年 7 月 25 日, 日雨量达 $412.5 \mathrm{~mm}, 23-25$ 日 $3 \mathrm{~d}$ 雨量达 $618.8 \mathrm{~mm}$. 测验河道高, 水流速大, 可达 $7 \mathrm{~m} / \mathrm{s}$ 以上,洪水时砾石滚动并有漂浮物. 流域内 受人类活动影响较少, 植被保护较好, 河流含沙 量小.

流域内共布设有 7 个雨量站 (寒婆坳、白果树、 白屋场、芦前、双冲、印心台、宝盖洞),6个土壤墑 情自动监测站 (寒婆坳、白果树、白屋场、芦前、双 冲、印心台) 和 1 个水文控制站 (宝盖洞水文站; $28^{\circ} 22^{\prime} \mathrm{N}, 113^{\circ} 44^{\prime} \mathrm{E}$ ) (图 2), 站网密度足够且分布 合理. 为了保证系统设备的协调工作和减小系统误 差,所有的土壤墑情测站均统一采用 ZNY.HDJ-1 墑/旱情自动化系统设备, 各测点 (测点深度分别为

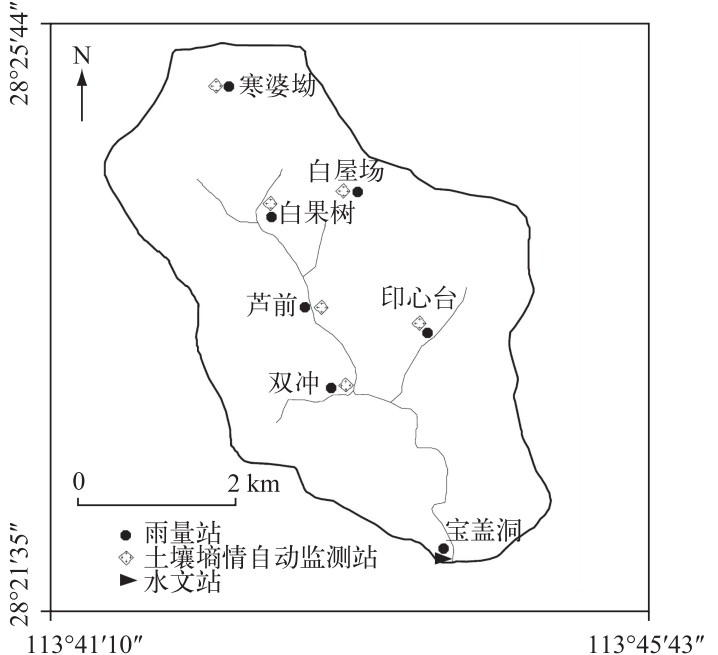

图 2 宝盖洞流域水系及站点分布

Fig. 2 The drainage and station distribution of Baogaidong Basin $20 、 40 、 60 \mathrm{~cm})$ 均采用相同的传感器探头. 流域水系 
及站点布设见图 2.

\section{2 土壤含水率观测资料分析}

本研究旨在利用观测的土壤墑情数据, 改进传统的模型结构, 设计基于实测土壤墑情资料的降雨径流 预报模型. 而实测资料总是存在误差的, 因此, 在将观测资料用于模型构建和模型参数率定前, 首先要对观 测资料进行合理性和可靠性分析，了解观测资料存在的问题. 资料分析主要从观测资料时间变化特征、土壤 含水率资料与降雨资料的相关性以及土壤含水率资料与蒸发资料的相关性三个方面展开. 本流域无蒸发资 料, 故借用附近流域双江口站 $\left(28^{\circ} 20^{\prime} 11.6^{\prime \prime} \mathrm{N}, 112^{\circ} 40^{\prime} 20.8^{\prime \prime} \mathrm{E}\right)$ 的蒸发观测资料. 不同深度各测点土壤含水率 观测值逐日变化情况如图 3 所示 (以芦前站为例), 芦前站逐日土壤含水率在时间序列上波动剧烈, 其他 5 个站情况均与该站类似. 各站逐日土壤含水率与降雨和蒸发之间的相关系数分别见表 1 和表 2 . 由表 1 和表 2 可以看出, 土壤含水率资料与降雨资料呈正相关关系, 与蒸发资料呈负相关关系, 但土壤含水率资料与降 雨和蒸发资料相关系数的绝对值都很小, 即土壤含水率资料与降雨和蒸发资料之间的相关性很差, 不能直 接用于模型计算, 必须经过抗差技术处理, 才可以加以利用.

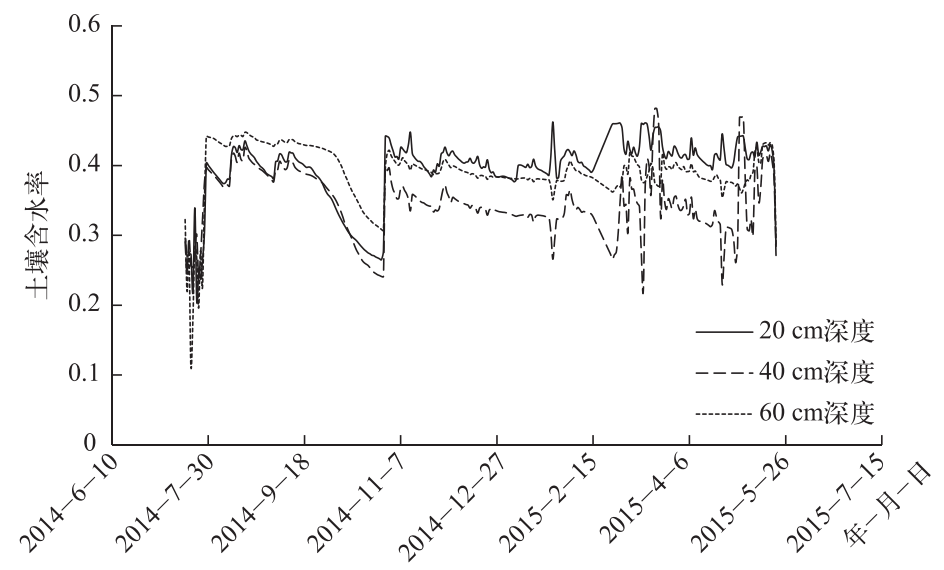

图 3 芦前站垂向各测点土壤含水率观测值逐日变化情况

Fig.3 Variation of daily measured soil moisture in vertical of Luqian station

表 1 逐日土壤含水率与降雨相关系数

Tab.1 The correlation coefficient between daily soil moisture and rainfall

\begin{tabular}{lcccc}
\hline \multirow{2}{*}{ 监测站 } & \multicolumn{3}{c}{ 相关系数 } \\
\cline { 2 - 5 } & $20 \mathrm{~cm}$ 深度与降雨 & $40 \mathrm{~cm}$ 深度与降雨 & $60 \mathrm{~cm}$ 深度与降雨 & 垂线平均与降雨 \\
\hline 白果树 & 0.117 & 0.034 & -0.019 & 0.069 \\
白屋场 & 0.152 & 0.100 & 0.076 & 0.143 \\
寒婆㘬 & -0.041 & -0.104 & 0.005 & -0.068 \\
芦前 & 0.167 & 0.128 & 0.086 & 0.145 \\
双冲 & 0.104 & 0.082 & 0.049 & 0.083 \\
印心台 & 0.101 & -0.168 & 0.108 & -0.133 \\
流域平均 & 0.100 & 0.012 & 0.051 & - \\
\hline
\end{tabular}

\section{3 模型计算结果}

本研究首先将实测土壤墑情资料转换为土壤含水率, 再研究实测土壤含水率与模型计算土壤含水量之 间的关系. 实测土壤含水率与模型计算土壤含水量之间,物理成因上讲是存在线性关系的. 由于实验流域观 测的土壤墑情资料存在诸多误差因素, 导致由土壤墑情资料转换而来的土壤含水率与模型计算土壤含水量 之间的相关性很差. 本研究采用全流域平均土壤含水率与新安江模型计算土壤含水量直接建立函数关系, 
表 2 逐日土壤含水率与蒸发的相关系数

Tab.2 The correlation coefficient between daily soil moisture and evaporation

\begin{tabular}{lcccc}
\hline \multirow{2}{*}{ 监测站 } & \multicolumn{3}{c}{ 相关系数 } \\
\cline { 2 - 5 } & $20 \mathrm{~cm}$ 深度与蒸发 & $40 \mathrm{~cm}$ 深度与蒸发 & $60 \mathrm{~cm}$ 深度与蒸发 & 垂线平均与蒸发 \\
\hline 白果树 & -0.059 & 0.109 & -0.053 & 0.051 \\
白屋场 & -0.111 & -0.057 & -0.192 & -0.138 \\
寒婆坳 & -0.306 & -0.148 & -0.111 & -0.241 \\
芦前 & -0.466 & 0.070 & -0.009 & -0.216 \\
双冲 & -0.429 & -0.176 & 0.053 & -0.078 \\
印心台 & -0.372 & 0.063 & -0.369 & -0.062 \\
流域平均 & -0.290 & -0.022 & -0.113 & - \\
\hline
\end{tabular}

其关系式为:

$$
W=522.92(\theta-0.30)+60
$$

式中, $W$ 为模型计算土壤含水量 $(\mathrm{mm}), \theta$ 为实测土壤含水率. 全流域平均土壤含水率与新安江模型计算土 壤含水量的关系见图 4.

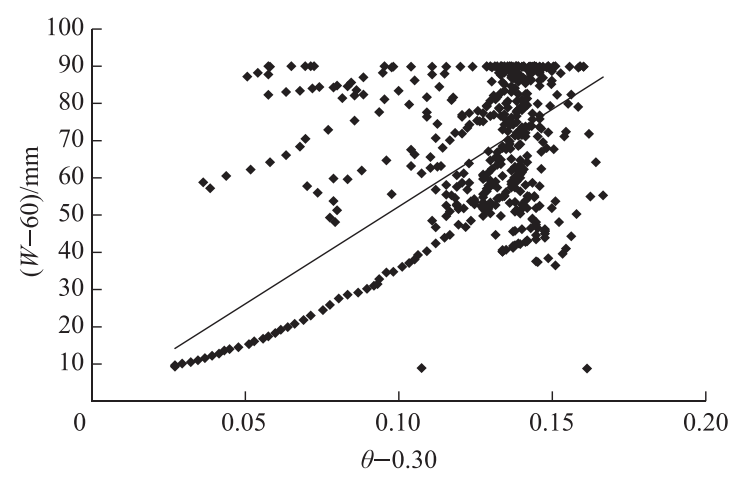

图 4 实测土壤含水率 $(\theta-0.30)$ 与土壤含水量 $(W-60)$ 的关系

Fig.4 The relationship between measured soil moisture $(\theta-0.30)$ and soil water content $(W-60)$ calculated by model

本研究选取宝盖洞流域 2014-2015 年 26 场 洪水作为模型检验资料. 用式 (11) 由实测土壤含 水率计算的土壤含水量, 用新安江模型模拟的洪 水结果见表 $3\left(R_{0}\right.$ 是次洪实测径流深, $e r$ 是计算径 流深相对误差, $Q_{\mathrm{p}}$ 是实测洪峰流量, $e q$ 是计算洪峰 流量相对误差).

利用 1.1 节介绍的土壤墑情资料抗差技术, 对 由式(11) 计算得到的土壤含水量 $W$ 进行抗差计 算, 得到抗差后的土壤含水量 $W_{\mathrm{r}}$. 将 26 场洪水初 始时刻的抗差计算土壤含水量 $W_{\mathrm{r}}$ 与新安江模型 计算得到的土壤含水量 $W_{\text {mod }}$ 比较, 建立抗差土壤 含水量 $W_{\mathrm{r}}$ 与模型计算土壤含水量 $W_{\text {mod }}$ 之间的关 系, 具体关系见图 5. 用经过抗差计算后的土壤含 水量 $W_{\mathrm{r}}$ 代人新安江模型计算的洪水结果见表 4.

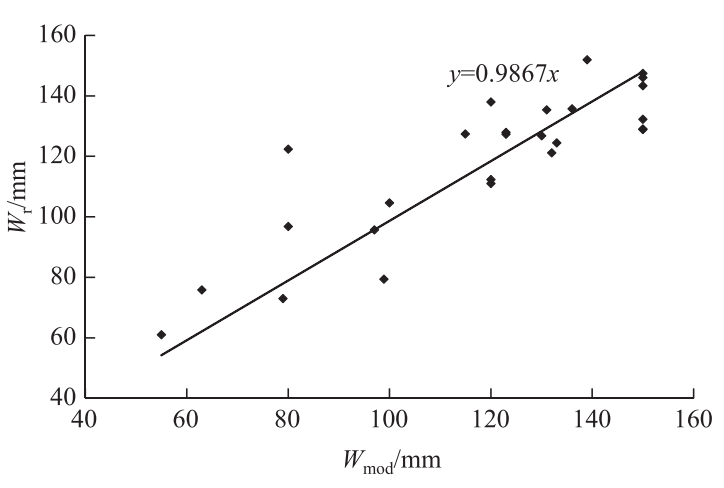

图 5 抗差含水率与模型计算的土壤含水量关系

Fig.5 The relationship between robust soil moisture and soil water content calculated by model 
表 3 实测土壤含水率直接用于模型计算的洪水模拟结果

Tab.3 The flood simulation results which are calculated by measured soil moisture

\begin{tabular}{cccccccccccc}
\hline 洪号 & $R_{0} / \mathrm{mm}$ & $e r / \%$ & $Q_{\mathrm{p}} /\left(\mathrm{m}^{3} / \mathrm{s}\right)$ & $e q / \%$ & 合格否 & 洪号 & $R_{0} / \mathrm{mm}$ & $e r / \%$ & $Q_{\mathrm{p}} /\left(\mathrm{m}^{3} / \mathrm{s}\right)$ & $e q / \%$ & 合格否 \\
\hline 31151204 & 34.9 & -24.1 & 3.5 & -5.7 & 不合格 & 31150528 & 50.9 & -4.3 & 12.8 & 5.5 & 合格 \\
31151115 & 40.5 & 6.4 & 4.5 & 20.0 & 不合格 & 31150526 & 16.0 & -23.8 & 7.8 & -17.9 & 不合格 \\
31151111 & 13.2 & 31.8 & 2.4 & 12.5 & 不合格 & 31150328 & 82.7 & 9.3 & 13.3 & 131.6 & 不合格 \\
31151110 & 15.4 & 44.2 & 2.4 & 16.7 & 不合格 & 31150321 & 23.4 & 48.7 & 2.0 & 300.0 & 不合格 \\
31151108 & 3.9 & -28.2 & 1.8 & -83.3 & 不合格 & 31150317 & 19.1 & 17.8 & 2.4 & 170.8 & 不合格 \\
31151004 & 21.1 & 25.1 & 3.0 & -33.3 & 不合格 & 31150313 & 15.4 & 114.3 & 2.0 & 180.0 & 不合格 \\
31150904 & 3.0 & 43.3 & 0.8 & -12.5 & 合格 & 31150225 & 21.8 & 88.5 & 1.8 & 105.6 & 不合格 \\
31150809 & 10.7 & -0.9 & 1.2 & -8.3 & 合格 & 31141129 & 4.3 & 67.4 & 0.6 & 116.7 & 不合格 \\
31150722 & 27.6 & 17.4 & 10.1 & -5.0 & 合格 & 31141106 & 6.9 & 56.5 & 1.1 & 9.1 & 不合格 \\
31150702 & 8.3 & -38.6 & 2.7 & -55.6 & 不合格 & 31141029 & 8.3 & 75.9 & 1.1 & 9.1 & 不合格 \\
31150620 & 177.5 & -49.0 & 26.1 & -23.4 & 不合格 & 31140817 & 68.9 & -32.4 & 7.0 & 35.7 & 不合格 \\
31150618 & 25.2 & -41.7 & 6.1 & -19.7 & 不合格 & 31140810 & 59.8 & -7.4 & 10.6 & -17.9 & 合格 \\
31150613 & 79.0 & -51.3 & 7.8 & -20.5 & 不合格 & 平均 & 36.0 & -13.0 & 5.8 & 11.9 & $5 / 26$ \\
31150607 & 98.5 & -36.2 & 16.5 & -22.4 & 不合格 & & & & & &
\end{tabular}

表 4 抗差土壤含水量用于模型计算的洪水模拟结果

Tab.4 The flood simulation results which are calculated by robust soil water content

\begin{tabular}{|c|c|c|c|c|c|c|c|c|c|c|c|}
\hline 洪号 & $R_{0} / \mathrm{mm}$ & $e r / \%$ & $Q_{\mathrm{p}} /\left(\mathrm{m}^{3} / \mathrm{s}\right)$ & $e q / \%$ & 合格否 & 洪号 & $R_{0} / \mathrm{mm}$ & $e r / \%$ & $Q_{\mathrm{p}} /\left(\mathrm{m}^{3} / \mathrm{s}\right)$ & $e q / \%$ & 合格否 \\
\hline 31151204 & 34.9 & -17.5 & 3.5 & -2.9 & 合格 & 31150528 & 50.9 & -10.2 & 12.8 & -0.8 & 合格 \\
\hline 31151115 & 40.5 & 21.2 & 4.5 & 40.0 & 不合格 & 31150526 & 16.0 & -27.5 & 7.8 & -55.1 & 不合格 \\
\hline 31151111 & 13.2 & -4.5 & 2.4 & -12.5 & 合格 & 31150328 & 82.7 & 18.3 & 13.3 & 107.5 & 不合格 \\
\hline 31151110 & 15.4 & -9.7 & 2.4 & -16.7 & 合格 & 31150321 & 23.4 & 7.7 & 2.0 & 5.0 & 合格 \\
\hline 31151108 & 3.9 & 74.4 & 1.8 & -16.7 & 不合格 & 31150317 & 19.1 & -1.0 & 2.4 & 4.2 & 合格 \\
\hline 31151004 & 21.1 & 35.5 & 3.0 & -20.0 & 不合格 & 31150313 & 15.4 & 1.3 & 2.0 & -10.0 & 合格 \\
\hline 31150904 & 3.0 & 16.7 & 0.8 & -37.5 & 不合格 & 31150225 & 21.8 & 38.5 & 1.8 & 44.4 & 不合格 \\
\hline 31150809 & 10.7 & -39.3 & 1.2 & -50.0 & 不合格 & 31141129 & 4.3 & 4.7 & 0.6 & 0 & 合格 \\
\hline 31150722 & 27.6 & 11.6 & 10.1 & -12.9 & 合格 & 31141106 & 6.9 & -11.6 & 1.1 & -36.4 & 不合格 \\
\hline 31150702 & 8.3 & -33.7 & 2.7 & -48.1 & 不合格 & 31141029 & 8.3 & 16.1 & 1.1 & -9.1 & 合格 \\
\hline 31150620 & 177.5 & -0.6 & 26.1 & -13.0 & 合格 & 31140817 & 68.9 & -10.9 & 7.0 & 5.7 & 合格 \\
\hline 31150618 & 25.2 & 0.8 & 6.1 & -1.6 & 合格 & 31140810 & 59.8 & -7.4 & 10.6 & -17.9 & 合格 \\
\hline 31150613 & 79.0 & -16.1 & 7.8 & 1.3 & 合格 & 平均 & 36.0 & -1.9 & 5.8 & -2.1 & $16 / 26$ \\
\hline 31150607 & 98.5 & -19.0 & 16.5 & -20.0 & 合格 & & & & & & \\
\hline
\end{tabular}

在抗差计算的基础上,采用 2.2 节介绍的土壤含水量系统响应反演修正方法,改进洪水初始土壤含水 量. 改进的洪水初始土壤含水量修正结果见表 5 . 表 5 中 $W_{\mathrm{U}}$ 为上层土壤含水量, $W_{\mathrm{L}}$ 为下层土壤含水量, $W_{\mathrm{D}}$ 为 深层土壤含水量. 加人土壤含水量系统响应反演修正方法后的洪水模拟结果见表 6 . 加人抗差技术和系统响 应反演修正方法后, 洪水合格率达到 92.3\%, 仅有 31151004 和 31151108 两场洪水模拟不合格 (表 6), 图 6 是 其中 2 场洪水 (不合格和合格各 1 场,洪号分别为 31151004 和 31151110 ) 的模型计算结果图.

\section{4 结果分析}

1) 对实测土壤含水率资料和雨洪资料分析发现, 实测土壤含水率资料在时间序列上波动剧烈, 土壤含 水率资料与降雨和蒸发资料的相关性很差. 鉴于此, 土壤含水率测量探针的埋设方式以及数据采集处理方 式还有待进一步验证和探讨. 
表 5 土壤含水量系统响应反演修正结果

Tab.5 The results of system response correction for soil water content

\begin{tabular}{cccccccc}
\hline 日期 & $W_{\mathrm{U}} / \mathrm{mm}$ & $W_{\mathrm{L}} / \mathrm{mm}$ & $W_{\mathrm{D}} / \mathrm{mm}$ & 日期 & $W_{\mathrm{U}} / \mathrm{mm}$ & $W_{\mathrm{L}} / \mathrm{mm}$ & $W_{\mathrm{D}} / \mathrm{mm}$ \\
\hline $2014-8-10$ & 0 & 70 & 50 & $2015-6-13$ & 20 & 80 & 50 \\
$2014-8-17$ & 3 & 80 & 50 & $2015-6-18$ & 18 & 80 & 50 \\
$2014-8-27$ & 8 & 80 & 50 & $2015-6-20$ & 20 & 80 & 50 \\
$2014-10-29$ & 0 & 13 & 50 & $2015-7-2$ & 15 & 80 & 50 \\
$2014-11-6$ & 2 & 80 & 50 & $2015-7-22$ & 20 & 80 & 50 \\
$2014-11-29$ & 0 & 70 & 50 & $2015-8-9$ & 0 & 73 & 50 \\
$2015-2-25$ & 0 & 30 & 50 & $2015-9-4$ & 0 & 49 & 50 \\
$2015-3-13$ & 17 & 80 & 50 & $2015-10-4$ & 3 & 80 & 50 \\
$2015-3-17$ & 0 & 73 & 50 & $2015-11-8$ & 0 & 70 & 50 \\
$2015-3-21$ & 0 & 50 & 50 & $2015-11-10$ & 0 & 80 & 50 \\
$2015-3-28$ & 0 & 30 & 50 & $2015-11-11$ & 6 & 80 & 50 \\
$2015-5-26$ & 20 & 80 & 50 & $2015-11-15$ & 9 & 80 & 50 \\
$2015-5-28$ & 20 & 80 & 50 & $2015-12-4$ & 20 & 80 & 50 \\
$2015-6-7$ & 20 & 80 & 50 & & & & 5 \\
\hline
\end{tabular}

表 6 土壤含水量系统响应反演修正的洪水模拟结果

Tab.6 The flood simulation results using soil water content corrected by system response curve

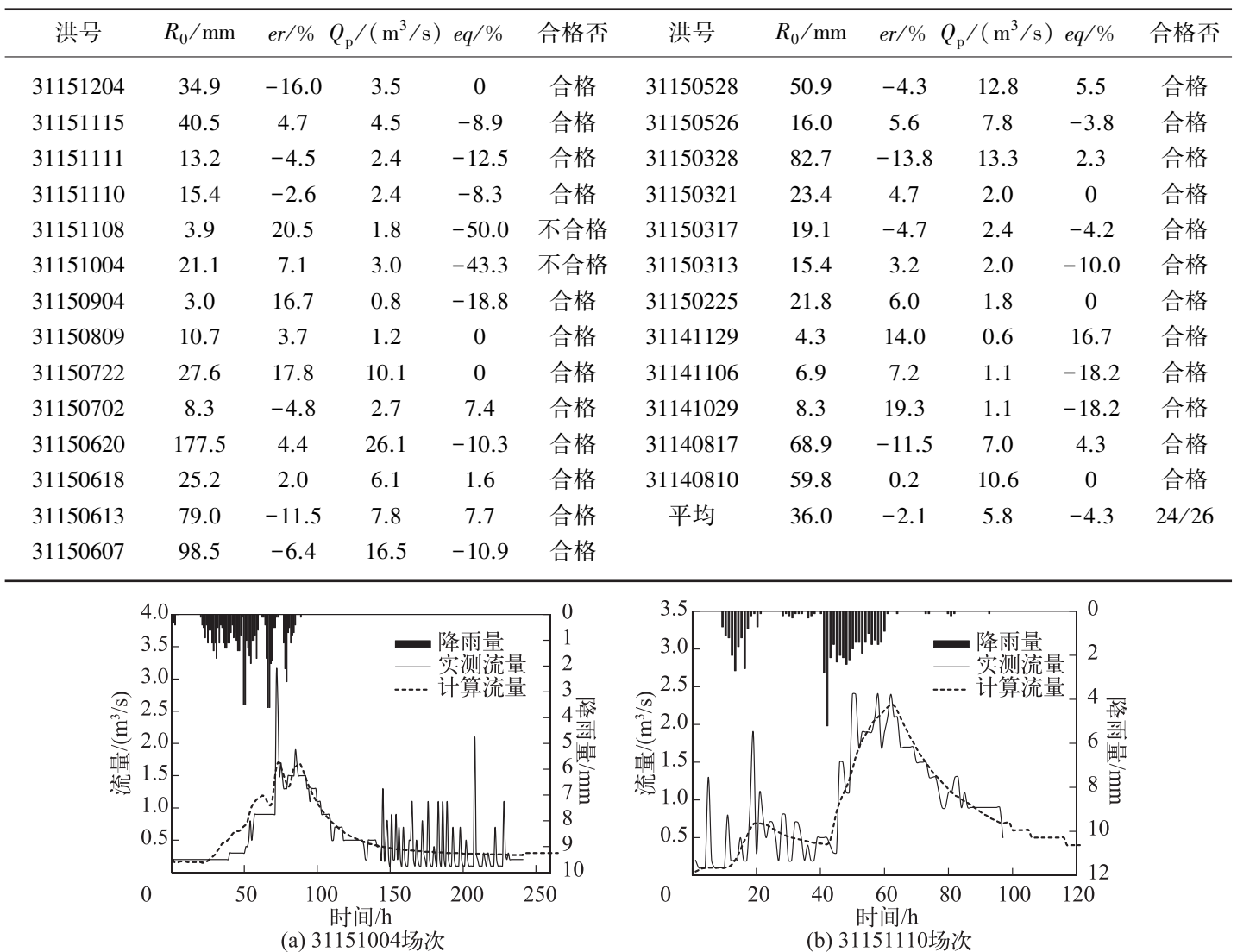

图 6 典型洪水的模型计算结果图

Fig.6 The model simulation results of two typical floods 
2) 实测土壤含水率与模型计算土壤含水量之间,物理成因上讲是存在线性关系的. 但由图 4 和表 3 结 果可以看出, 实测土壤含水率与模型计算土壤含水量之间相关性很差,无明显的函数关系. 使用计算的土壤 含水量用新安江模型计算的 26 场洪水结果, 效果很不理想, 其合格率低于 $20 \%$. 说明实测土壤含水率资料 观测误差很大, 不能直接用于模型计算. 实时土壤含水率数据与模型使用的土壤含水量之间的对应关系还 需要大量实测数据的分析和研究.

3) 比较表 4 和表 3 可得, 采用抗差估计对观测资料进行处理后, 用抗差土壤含水量代人新安江模型计 算的洪水模拟结果比较抗差前, 洪水模拟精度有明显提高, 合格率由 $19.2 \%$ 提高到了 $61.5 \%$, 说明抗差估计 能有效降低观测误差对土壤含水量估计的影响. 但总体精度还是很低,模型模拟精度还低于乙等方案.

4) 比较表 6 和表 4 可得, 采用土壤含水量系统响应反演修正方法, 改进洪水初始土壤含水量, 洪水模拟 结果整体上有很大提高, 洪水合格率达到了 $92.3 \%$, 整体方案达到并超过了甲级. 相对来说次洪径流深提高 的幅度比洪峰大, 这是合理的, 因为初始土壤含水量的改进, 最直接的改进结果是次洪计算径流深, 通过改 进径流深再影响洪峰. 而土壤含水量系统响应误差修正的目标信息是洪量,所以洪量的提高幅度比洪峰大.

5)计算结果可知,31151004 场次洪水计算洪峰流量偏小, 导致洪水模拟不合格 (表 6), 但 31151004 场 次洪水的实测洪峰明显存在观测粗差, 实际的洪峰应该与计算洪峰相近 (图 6a), 而另一场模拟不合格的洪 水情况与此类似. 而 31151110 场次洪水实测流量过程波动很大, 应该是由于观测误差引起的 (图 6b). 总体 来说,改进后的模型的洪水模拟结果较好.

\section{4 结论}

本文提出了一种基于实测土壤墑情的水文预报方法, 将实时监测到的土壤墑情转化为流域水文模型可 以直接使用的土壤含水量, 论证了将土壤墑情资料用于实时预报的可行性. 建立了基于实测土壤墑情的降 雨径流预报模型, 并加人土壤含水率误差抗差估计技术和土壤含水量系统响应修正方法, 提高了将土壤墑 情应用于模型计算的模拟精度和系统的稳定性. 将该模型应用于实验流域——宝盖洞流域进行验证,洪水 模拟合格率达到了 $92.3 \%$, 整体模拟效果达到甲级. 这表明将土壤含水量实时监测数据用于水文模型预报 是可行的,利用实测土壤墒情资料改进的三水源新安江模型可以在湿润半湿润地区实时洪水预报中进行推 广应用.

\section{5 参考文献}

[ 1 ] Mi Sujuan, Tang Jiakui, Zhang Xianfeng et al. Soil moisture assimilation based on Variable Infiltration Capacity and Ensemble Kalman Filter. Geography and Geo-Information Science, 2013, 29(1): 91-95. [米素娟, 唐家奎, 张显峰等. 基 于 VIC 模型与集合卡尔曼滤波的土壤水分同化研究. 地理与地理信息科学, 2013, 29(1) : 91-95.]

[ 2 ] Shu Huilian. The soil moisture error correction method based on system response curve of flood forecasting model[Dissertation]. Nanjing: Hohai University, 2016. [束慧连. 模型土壤含水量的系统响应曲线修正方法 [学位论文]. 南京: 河 海大学, 2016.]

[ 3 ] Jackson TJ, Schmugge TJ, Nicke AD et al. Soil moisture updating and microwave remote sensing for hydrological simulation. Hydrological Sciences Journal, 1981, 26(3) : 305-319.

[ 4 ] Pauwels VRN, Hoeben R, Verhoestn EC et al. The importance of the spatial patterns of remotely sensed soil moisture in the improvement of discharge predictions for small scale basins through data assimilation. Journal of Hydrology, 2001, 251: 88-102.

[ 5 ] Parajka J, Naemi V, Bloschl G et al. Assimilating scatterometer soil moisture data into conceptual hydrologic models at coarse scales. Hydrology and Earth System Sciences, 2006, 10: 353-368.

[ 6 ] Bao Weimin, Wang Hao, Zhao Chao et al. Robust estimation of AR model parameters. Journal of Hohai University: Natural Sciences, 2006, 34(3) : 258-261. [包为民, 王浩, 赵超等. AR 模型参数的抗差估计研究. 河海大学学报: 自然 科学版, 2006, 34(3): 258-261.]

[ 7 ] Bao Weimin, Ji Haiyang, Hu Qimei et al. Robust estimation theory and its application to hydrology. Advances in Water Science, 2003, 14(4) : 528-532. [包为民, 愁海祥, 胡其美等. 抗差理论及在水文学中的应用. 水科学进展, 2003,14 (4) : 528-532.] 
[ 8 ] Shen Dandan, Bao Weimin, Liu Kexin et al. Study on parameter robust estimation for Muskingum Model. China Rural Water and Hydropower, 2016, (7) : 72-74. [沈丹丹, 包为民,刘可新等. 马斯京根汇流参数抗差估计研究. 中国农村水 利水电, 2016, (7): 72-74.]

[ 9 ] Zhao Chao. Robust real-time flood forecasting system[ Dissertation]. Nanjing: Hohai University, 2006. [赵超. 流域实时 洪水抗差预报系统研究 [学位论文]. 南京: 河海大学, 2006.]

[10] Tuo Liwen, Wu Youping. Weighting function selection of a new robust estimation method. Geomatics and Spatial Information Technology, 2008, 31(1) : 181-182, 185. [脱立文, 吴友平. 一种新的稳健估计方法的权函数选取. 测绘与空 间地理信息，2008，31(1) : 181-182，185.]

[11] Si Wei, Bao Weimin, Gupta HV. Updating real-time flooding forecasts via the dynamic system response curve method. Water Resources Research, 2015, 51: 1-17.

[12] Bao Weimin, Asce M, Si Wei et al. Flow updating in real-time flood forecasting based on runoff correction by a dynamic system response curve. Journal of Hydrologic Engineering, 2014, 19(4) : 747-756.

[13] Si Wei, Bao Weimin, Qu Simin. Runoff error correction in real-time flood forecasting based on dynamic system response curve. Advances in Water Science, 2013, 24(4) : 497-503. [司伟, 包为民, 矍思敏. 洪水预报产流误差的动态系统响 应曲线修正方法. 水科学进展, 2013, 24(4): 497-503.]

[14] Bao Weimin, Liu Kexin, Zhang Xiaoqin et al. Runoff error proportionality coefficient correction method based on system response. Advances in Water Science, 2014, 10: 476-482. [包为民, 刘可新, 张小琴等. 产流误差比例系数的系统响 应修正方法. 水科学进展, 2014, 10: 476-482.]

[15] Liu Kexin, Bao Weimin, Zhang Xiaoqin et al. A system response correction method with runoff error smooth matrix. Journal of Hydraulic Engineering, 2015, 46(8): 960-966. [刘可新, 包为民, 张小琴等. 产流误差平稳矩阵的系统响应 修正方法. 水利学报, 2015, 46(8): 960-966.]

[16] Bao Weimin. Hydrological forecasting. Beijing: China Water and Power Press, 2011: 143-163. [包为民. 水文预报. 北 京: 中国水利水电出版社, 2011: 143-163.]

[17] Bao Weimin, Zhang Xiaoqin, Zhao Liping. Parameter estimation method based on parameter function surface. Technological Sciences, 2013, 56(6): 1485-1498.

[18] Si Wei, Bao Weimin, Qu Simin. Problem of objective function of error square sum in parameter calibration. Water Resources and Power, 2013, 31(8) : 19-21. [ 司伟, 包为民, 矍思敏. 误差平方和目标函数在参数率定过程中遇到的 问题. 水电能源科学, $2013, \mathbf{3 1}(8): 19-21$. ]

[19] Zhang Kun, Bao Weimin, Zhao Liping et al. Optimization algorithm of HBV Model based on linearized parameter calibration and its application. Water Resources and Power, 2013, 31(9) : 8-11. [张坤, 包为民, 赵丽平等. 基于参数线性化 率定法的 HBV 模型的优化算法及应用. 水电能源科学, 2013, 31(9) : 8-11.]

[20] Bao Weimin, Zhang Kun, Wang Hongyan et al. Application of the linearized parameter calibration method for HBV-IWS model. Journal of Hydraulic Engineering, 2013, 44(10): 1210-1216. [包为民. 张坤, 王红艳等. 参数线性化率定方法 在 HBV-IWS 模型中的应用. 水利学报,2013, 44(10): 1210-1216.] 